\title{
Study on the Effect of Titanate Coupling Agent on the Impact Properties improvement of Polystyrene/TiO2 Nanocomposites Dongmei Zhang ${ }^{1}$, Xiaoyan Wang $^{2}$ \& Xinrong Kan ${ }^{1}$ \\ ${ }^{1}$ tangshan industrial vocational technical college, tangshan 063020 ,china \\ ${ }^{2}$ Qinggong College, Hebei United University, tangshan 063000,china
}

Keywords: $\mathrm{TiO}_{2}$, titanate coupling agent, polystyrene, impact properties.

\begin{abstract}
A study is carried out to investigate the influences of compounding process and surface treatment on nanometre-sized $\mathrm{TiO}_{2}$ filled polystyrene. The compounding process is discussed with a torque rheometer. The $\mathrm{TiO}_{2}$ filler is surface-treated with a liquid titanate coupling agent. The effects of coupling agents on the mechanical, morphological, and thermal stability properties of $\mathrm{TiO}_{2}$ /polystyrene(PS) nanocomposites were studied. Nanocomposites of different weight fractions are prepared, and their impact properties are evaluated. The unnotched impact strength increased. Surface treatment of $\mathrm{TiO}_{2}$ filler generally yielded nanocomposites of higher impact strength than untreated system.
\end{abstract}

\section{Introduction}

It has been a widespread practice to incorporate inorganic nanoparticals into plastics and elastomers to extend the matrix or to enhance certain properties. It is generally recognised that the particle size and shape, surface characteristics, fraction of filler can greatly affect the performance of the composites. In a highly filled polymer system, a major problem is the poor dispersion of the filler in the matrix. Therefore, the application of some coupling agents, in order to treat interaction between the matrix and filler, have been used to improve the dispersion of filler and to enhance the mechanical strength of the coposites by reinforce interface adhesion.

Surface of inorganic particles often treated by coupling agents such as silane, titanate, aluminate and zirconium coupling agents[1-5]. At present, several methods used in valuation of surface treatment are contact angle of interface [36, saturation speed of capillary[6], sedimentation volume[7], surface electric property of zeta electric potential[8].

In this paper, titanate coupling agents are chosen to surface treatment of $\mathrm{TiO} 2$ by solution methods. Several characterization methods are applied in qualitatively and quantitatively analyzing the results of surface treatment. Mechanical properties of composites of the inorganic nanoparticles and PS are also examined. Moreover, the activities of untreated and treated inorganic nanoparticles are compared.

\section{Experimental}

\section{Materials}

TiO2 is obtained from Shangdong Origine Nanomaterial Engineering Co.Ltd. The characteristics of the fillers are depicted in Table 1 . The polymer selected for the study is polystyrene, which is obtained from beijing petrochemical corporation. Surface treatment of the $\mathrm{TiO} 2$ power is performed by the titanate coupling agent, isopropyl tris(dioctanpyrophosphate) titanate(JN-2), from jinai assistant Co.Ltd, changzhou.

Table 1: Characteristic of titanium dioxide

\begin{tabular}{ll}
\hline Properties & Values \\
\hline Density & $0.4 \mathrm{~g} / \mathrm{cm}^{3}$ \\
Average particle diameter & $10 * 40 \mathrm{~nm}$ \\
Specific area & $\geqslant 150 \mathrm{~m} 2 / \mathrm{g}$ \\
\hline
\end{tabular}




\begin{tabular}{ll}
\hline Color & white \\
Purity & $\geqslant 99 \%$ \\
\hline
\end{tabular}

\section{Surface treatment of $\mathrm{TiO} 2$ power}

The titanium dioxide particles are first heated in an oven at $60{ }^{\circ} \mathrm{C}$ for $4 \mathrm{~h}$ to remove the moisture and then mixed with $10 \sim 20$ weight ratio of the coupling agent. The $1.0 \%$ solution of the titanate coupling agent in isopropyl alcohol is used for applying to TiO2. The ultrasonic dispersion of the filler is also in isopropyl alcohol for $30 \mathrm{~min}$, and the concentration of the solution is $10 \mathrm{~g} / 100 \mathrm{ml}$. Then, mixing and strring them at $60^{\circ} \mathrm{C}, 70^{\circ} \mathrm{C}, 80^{\circ} \mathrm{C}$ for $1 \sim 3 \mathrm{~h}$ to ensure uniform distribution. At last, the $\mathrm{TiO} 2$ power is separated from the isopropyl alcohol and is dried in vacuum desicator. According to the data, when $\mathrm{TiO} 2$ is treated by $10 \mathrm{wt} . \%$ of titanate-coupling agents at $70^{\circ} \mathrm{C}$ for $2 \mathrm{~h}$, the lipophilicity of $\mathrm{TiO} 2$ is the best.

\section{Mixing method}

Polystyrene is mixed with the untreaded or treaded filler power using a torque rheometer(model XSS-300). The compositions of the fillers are $0 \%, 1 \%, 2 \%, 3 \%, 5 \%$ and $7 \%$ by weigh, mixing conditions of $185^{\circ} \mathrm{C}, 65 \mathrm{rpm}$. Identical instrumental settings are maintained throughout all the experiments and torque vs time data are recorded for each mixing process.

\section{Measurement of impact properties}

The compounded matter is then vulcanized using a sulfur system by a press-curing method (compression molding machine) at $180^{\circ} \mathrm{C}$ for $20 \mathrm{~min}$ in a chrome-plated mold. Then the plate is cut into pieces of size $50 \times 6 \times 3 \mathrm{~mm}$ for the unnotched impact test .

\section{Results and discussion}

\section{FT-IR analysis}

The IR spectra of the treated $\mathrm{TiO} 2$ by $\mathrm{JH}-2$ (a) and the untreated $\mathrm{TiO} 2$ (b) are shown in Fig.1. The peaks at $1000 \sim 1100 \mathrm{~cm}-1$ is the characteristic absorption peak of Ti-O, the broad peaks at $3426 \mathrm{~cm}-1$ and $1632 \mathrm{~cm}-1$ are the stretching vibrations peak and the bending vibrations peak of $\mathrm{O}-\mathrm{H}$ at the surface of $\mathrm{TiO} 2$ power. In the spectra of $\mathrm{JN}-2$, there appear the characteristic absorption peaks of methylene and methyl at $2926,2851 \mathrm{~cm}-1$ and the broad stretching vibrations peak of carbonyl group at 1600-1700 $\mathrm{cm}^{-1}$ of the pure aluminate-coupling agent, which also exist in the spectra of treated TiO2. It indicates that the functional groups of titanate coupling agent have reacted with hydroxyl groups on the surface of $\mathrm{TiO} 2$ and the coupling agent molecules are bonded to the surface to form an organic layer.

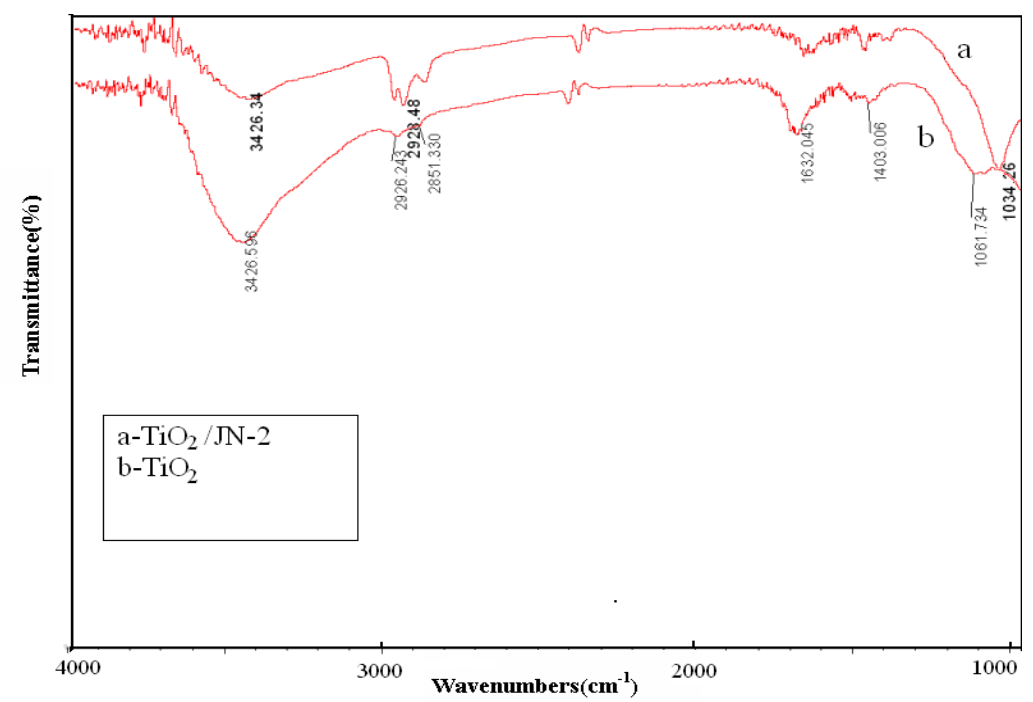

Fig.1: The IR spectra of $\mathrm{TiO}_{2}$ : (a) treated by JH-2; (b) untreated 


\section{Methodology}

Since torque is an indicator of viscosity, which reveals relative rheological behavior of composites, the effect of filler loading or surface treatment on the rheological properties of the composites can be investigated using torque vs time data at stabilization conditions. The methodology used for the experimental tests is the following:

1) Characterization of both the resin and the $\mathrm{TiO} 2$ power(in its different percentages) by means of the torque rheometer. The percentages of $\mathrm{TiO} 2$ introduced are $0 \%, 1 \%, 2 \%$ by weight;

2) The methodology of he nanocomposite with $2 \mathrm{wt} \% \mathrm{TiO} 2$ (treated and untreated) filler loaded.

Torque profiles are presented in fig.2, fig.3.The torque vs time data for the PS-TiO2 nanocomposites were recorded at mixing temperature of $185{ }^{\circ} \mathrm{C}$, rotor speed of $65 \mathrm{rpm}$ and mixing time of $10 \mathrm{~min}$. Fig. 2 and fig.3 illustrate torque vs time datas of the treated filler PS nanocomposites and compares with the untreated filler PS matrix. When stabilization values were compared, it was clearly seen that the incorporation of fillers was accompanied by an decrease in the stabilization torque for all the samples applied. The decrease in torque values with surface treatment can be explained by enhanced interactions between the fiber and the polymer. Chemical bonds formed with employment of surface treatment would have increased shearing between the fiber and the matrix, hence, the stabilization torque value attained.

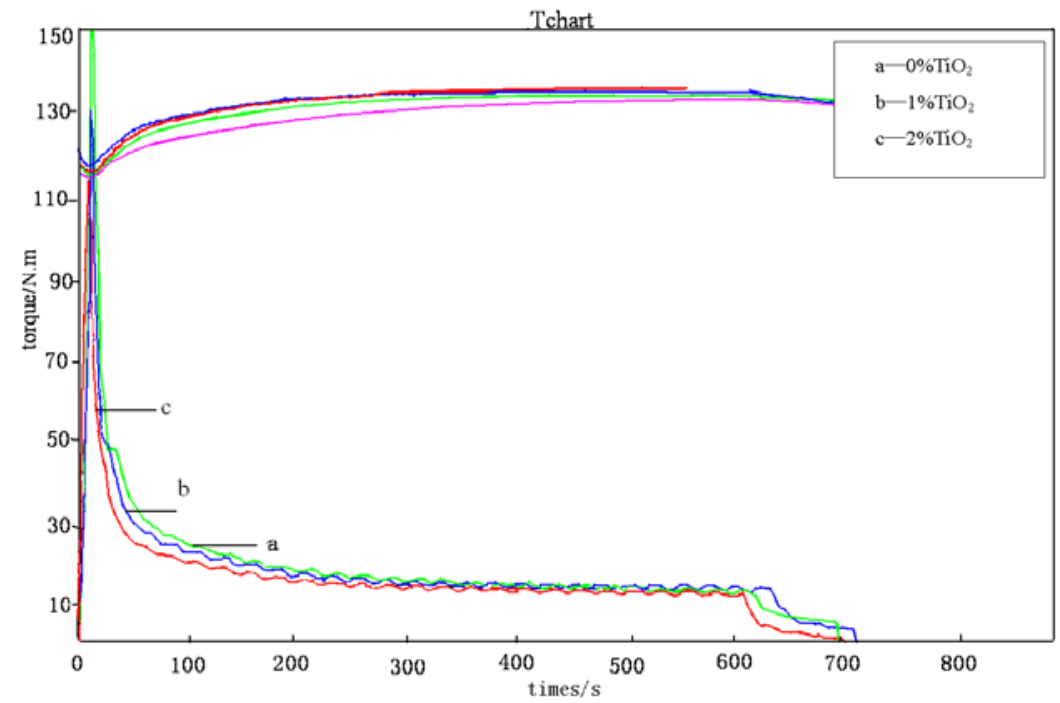

Fig.2: Rheological curves of the nanocomposite in different percentages of $\mathrm{TiO}_{2}$

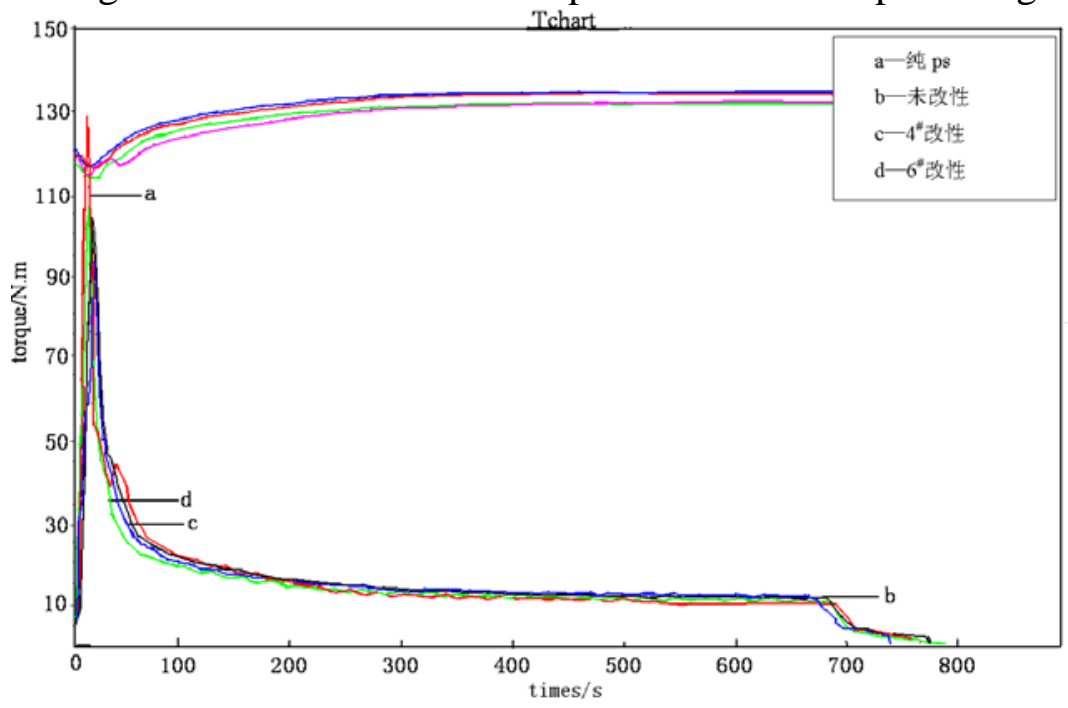

Fig.3: Rheological curves of the nanocomposite with $2 \mathrm{wt} \% \mathrm{TiO}_{2}$ fiber loaded (treated and untreated) 


\section{Impact strength}

The impact strength of a filled polymer depends on the degree of polymer-filler adhesion[9], Other factors such as microscale morphological changes in a polymer that are caused by the filler affect the impact strength of filled polymers. The presence of the filler may also cause a change in the fracture mechanism during impact from that commonly observed in the unfilled polymer.

Fig.4 shows the variation of impact strength with differenent of the untreated filler content. Impact strength is found to increase with filler content, results are in good agreement with the torque data and here the maximum value is attained at $2 \mathrm{wt} \%$ of filler loading. The increase in toughness at lower concentrations of filler may be due to the local microplastic deformation arising from the microscopic cavities around the filler and the filler slows the rate of crack growth is the formation of crazes in the crack tip. The decrease in toughness at higher filler concentrations is due to limited plastic flow of the matrix, the ductile matrix is replaced by the rigid dispersed particulates. And the existence of higher filler concentrations would be forming agglomerated particles.

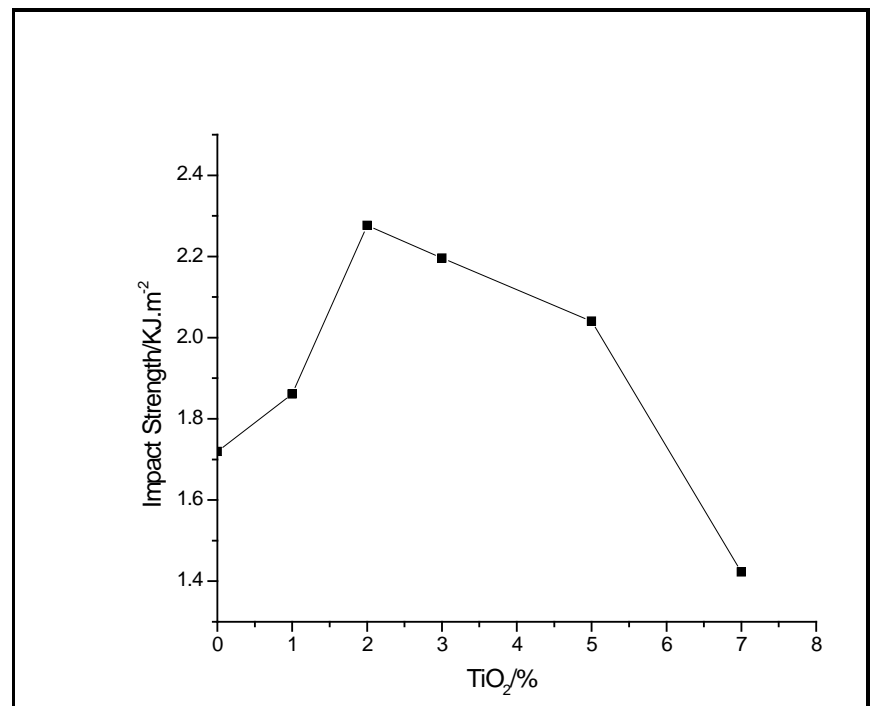

Fig.4: Impact strength as a function of filler content

Table 2 show the impact strength of the treated and untreated filler when the filler loading is 2 wt.\% of the composites. The impact strength of pure polystyrene, which is prepared in the same mixing condition,is $1.78 \mathrm{KJ} / \mathrm{m} 2$. By the use of titanate coupling agent, one can achieve best impact strength, that is, the impact strength of treated $\mathrm{TiO} 2$ is about 1.38 times higher than that of untreated $\mathrm{TiO} 2$ nanocomposites. The titanate coupling agent acts as a link between the filler and the matrix and forms a strong interface or adhesion between the filler and matrix resin.

Table2: The impact strength of the treated filler and untreated filler

\begin{tabular}{llll}
\hline Compounds & $\begin{array}{l}\text { Mixing } \\
\text { temperature/ } /{ }^{\circ} \mathrm{C}\end{array}$ & $\begin{array}{l}\text { Rotor speed } \\
/ \mathrm{rpm}\end{array}$ & $\begin{array}{l}\text { Impact } \\
\text { strength } \\
/ \mathrm{KJ}^{-2}\end{array}$ \\
\hline untreated $\mathrm{TiO}_{2}$ & 185 & 65 & 2.28 \\
Treated $\mathrm{TiO}_{2}$ & 185 & 65 & 3.15 \\
\hline
\end{tabular}

\section{Interpolation function}

The DTA-TG curves of the nanocomposite PS-TiO2 along with those of pure PS in pyrolytic conditions are presented in Fig.10. Under pyrolytic conditions, the thermal stability of the nanocomposite PS-TiO2 is enhanced relative to that of pure polystyrene. The onset temperature of the degradation is about $10^{\circ} \mathrm{C}$ higher for the nanocomposites than for the pure polystyrene.The final residues of PS - TiO2 observed in the degradation conditions (about 2 wt.\%) can be assigned to the residue of $\mathrm{TiO} 2$. In the case of nanocomposite, our results suggest that the role of $\mathrm{TiO} 2$ is to promote char during the degradation of the material. 


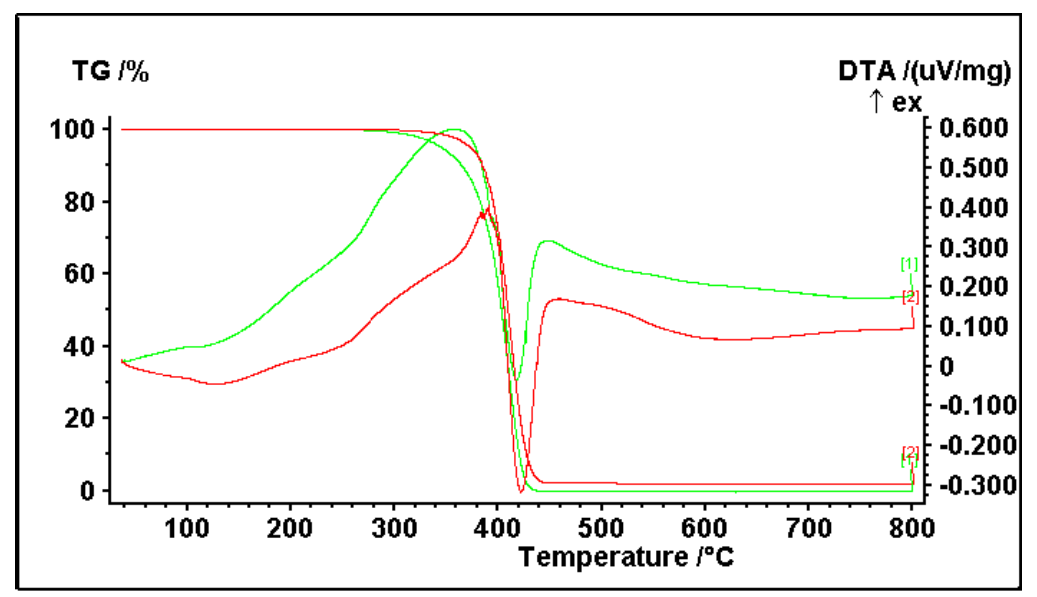

Fig.5: DTA-TG curves of composites: [1] pure polystyrene; [2] $\mathrm{TiO}_{2} /$ polystyrene

\section{Conclusion}

In the work, we have shown the effect of different parameters, such as filler content and the surface treatments of filler, on the mechanical properties of $\mathrm{TiO} 2$ reinforced polystyrene nanocomposites. The best value of impact strength is obtained while the filler loading is 2 wt.\%. Significant improvements in impact strength are observed for titanate treated TiO2 polystyrene nanocomposites. Improvement in mechanical properties is enhanced by titanate coupling agents due to the formation of a strong interface or adhesion between the filler and matrix resin.

\section{References}

[1] Q.X. Wanq, B.Z. Sonq, H.Z. Li, J. Inorg. Mater. 17 (2002), p. 953.

[2] A.W. Chuah, Y.C. Leong, S.N. Gan, Eur. Polym. J. 36 (2010), p. 789.

[3] C.M. Vaz, R.L. Reis, A.M. Cunha, Biomaterials 23 (2012), p. 629.

[4] A. Voelkel, T. Grzeskowiak, Coll. Surf. Part A 208 (2006), p. 177.

[5] C. Edser, Plast. Addit. Compd. 5 (2003), p. 40.

[6] S.L. Zheng, Surface Modification of Powder, Chinese Building Materials Industry Press, Beijing (2005).

[7] C.M. Liauw, G.C. Lees, S.J. Hurst, R.N. Rothon, S. Ali, Composites A 29A (2010), p. 1313.

[8] J.H. Jean, H.R. Wang, J. Am. Ceram. Soc. 83 (2000), p. 277.

[9] T. Vu-Khanh, J. Bowman, J.C. Behiri and W. Bonfield. Plast. Rubber Process. Appl. 4 (2008), p. 261. 